\title{
O Movimento de Reconceituação do Serviço Social no Pará: entre conservadorismos e resistências
}

\author{
The Reconceptualization Movement of Social Work in Pará: between conservatives and \\ resistance
}

\author{
Francisco dos Santos Neto* \\ Reinaldo Nobre Pontes** \\ Cilene Sebastiana Braga***
}

\begin{abstract}
Resumo: Este trabalho é um estudo sobre os fundamentos teórico-metodológicos do Serviço Social no período da Reconceituação no Pará. Objetivou-se analisar o processo de reconceituação no Pará a partir da visão de docentes que viveram esse momento. A coleta de dados ocorreu por meio de pesquisa bibliográfica, documental e de entrevistas semiestruturadas com três docentes que vivenciaram esse processo. $O$ estudo demonstrou que houve diferentes e antagônicas influências teóricas (positivista, fenomenológica e marxista) que interpretaram a profissão e sua legitimidade na sociedade burguesa, bem como influenciaram gerações de assistentes sociais formados na UFPA, alertando à comunidade cientifica desta área especializada que o estudo dos fundamentos do Serviço Social na cena contemporânea é condição sine qua non para (re) afirmar a direção social crítica e revolucionária desta profissão.
\end{abstract}

Palavras-chave: Serviço Social. Reconceituação. Teorias Sociais. Capitalismo Estado.

Abstract: This work is a historical study about the theoretical bases of Social Work during the reconceptualization period in the state of Pará. The objective was to analyze the reconceptualization process in Pará from the perspective of teachers who lived this moment. Data collection took place through bibliographic, documentary research and semi-structured interviews with three college professors who experienced this process. The study demonstrated that there were different and antagonistic theoretical influences (positivist, phenomenological and Marxist) that interpreted the profession and its legitimacy in bourgeois society, as well as influenced several generations of social workers graduated from UFPA, alerting the scientific community of this specialized area that the study of fundamentals of Social Work in the contemporary scene is a sine qua non condition to (re) affirm the critical and revolutionary social direction of this profession.

Keywords: Social Work. The reconceptualization. Social Theories. Capitalism. State.

\footnotetext{
* Assistente Social da Secretaria de Administração Penitenciaria do Estado do Pará e Mestrando do Programa de Pós-Graduação em Serviço Social da Universidade Federal do Pará

** Professor associado 1 da Faculdade de Serviço Social dos cursos de graduação em Serviço Social e Programa de Pós Graduação em Serviço Social - PPGSS

*** Professora Adjunta da Faculdade de Serviço Social dos cursos de graduação em Serviço Social e Programa de Pós Graduação em Serviço Social - PPGSS
} 


\section{Introdução}

Este trabalho objetiva apresentar aspectos históricos e teórico-metodológicos acerca da implantação do Serviço Social no Pará, assim como do período do chamado processo de Reconceituação da profissão no Estado.

O estudo sobre os fundamentos do Serviço Social configura-se, sobretudo na cena contemporânea, como um dos maiores desafios para o conjunto dos intelectuais dessa área especializada. É notório o esforço que muitas elaborações teóricas vêm fazendo para compreender as particularidades históricas e teórico-metodológicas do Serviço Social brasileiro; notadamente a mais expressiva obra nesse sentido é o livro da professora Marilda lamamoto, intitulado: Relações Sociais e Serviço Social no Brasil (1995).

É na órbita desses esforços que se inscreve este trabalho, que busca compreender as particularidades históricas e, sobretudo, teórico-metodológicas do Serviço Social no Pará, e no processo da denominada "Reconceituação".

Para a coleta de dados realizamos pesquisa bibliográfica, documental e entrevista com três docentes aposentadas da UFPA que viveram esse processo à época. A escolha se fez pautada em experiências vivenciadas pelo pesquisador em campo, instruído por conhecimentos científicos entre o objeto estudado e o corpus a ser pesquisado. (FONTANELA et al, 2011).

Esse trabalho foi dividido em três momentos. No primeiro deles, apresentaremos as dimensões conjunturais e estruturais do surgimento do Serviço Social no Pará, situando sua gênese no contexto da reprodução das relações sociais capitalistas na cidade de Belém em 1950.

Em seguida, exibem-se as particularidades do movimento de reconceituação do Serviço Social no Pará, articuladamente ao mesmo movimento no Brasil. A bibliografia para subsidiar este estudo no Pará é muito limitada, por isso buscou-se fontes primárias por meio da pesquisa de campo, apresentando a visão de docentes que vivenciaram esse momento para chegar a aproximações mais confiáveis dessa realidade histórica. 


\section{Contexto histórico do surgimento do Serviço Social no Pará em meio e ao processo de constituição do capitalismo no estado.}

Para entender o surgimento de uma profissão em determinado espaço/tempo, fazse necessário, segundo lamamoto (1995), apreender o movimento no qual e através do qual se engendraram e se renovaram as relações sociais que particularizaram uma dada formação social capitalista. Partindo dessa premissa se apresentará de forma breve as estratégias de desenvolvimento elaboradas para a Amazônia desde meados do século XX, com o declínio dos dois ciclos da borracha, uma vez que estes determinantes históricos se relacionam diretamente com a emergência da institucionalização do Serviço Social na Amazônia e em particular no Estado do Pará (RIBEIRO, A. SCHNEIDER, L. E ANDRADE, C, 2013).

Ainda segundo Ribeiro, Schneider e Andrade (2013) os ciclos da borracha na Amazônia fizeram parte de um dos principais momentos econômicos da região e tiveram forte intervenção do capital internacional. Sabe-se que o látex ganha uma grande importância de mercado na segunda revolução industrial, na indústria automobilística; nesse sentido o ciclo da borracha representou um marco na expansão do capital industrial e financeiro na Amazônia. Sobre esta temática Arbex Junior (2005, p. 31) afirma que "as primeiras incursões sobre o tema Amazônia estavam associadas às riquezas produzidas pela cultura da borracha".

Diante de uma conjuntura marcada pela economia da borracha em alta, muitos trabalhadores vieram para a região, causando um grande inchaço populacional; o mesmo autor afirma que neste período, entre 1900 e 1920, a população mais que dobrou, passando de 330.000 para cerca de 1,5 milhão de pessoas. Muitos desses trabalhadores morreram em construção de estradas e outros projetos que aqui se instalavam, tal como a construção da Estrada de ferro Madeira-Mamoré, na qual cerca de 30 mil pessoas morreram. (RIBEIRO, SCHNEIDER E ANDRADE, 2013, p. 02).

Especialmente no Estado do Pará é onde vai se concentrar o maior índice de desigualdades sociais. Segundo o IBGE - Instituto Brasileiro de Geografia e Estatística - (1966), a capital do Pará teve um crescimento de em média 118,61\% de sua população entre 1940 e 1960, e esse crescimento desordenado está imbricado ao avanço das relações hegemônicas do capitalismo. Nesse sentindo Oliveira (1988) afirma que: 


\begin{abstract}
Sabe-se, que neste período não se registra na cidade nenhum empreendimento de grande porte capitalista. Pode-se supor que [...] a iniciativa privada na exploração mineral da região tem um efeito repercutido sobre Belém, entreposto principal do movimento de mercadoria, inclusive de força de trabalho. Aliás, Belém vem exercendo esse papel desde o $1^{\circ}$ ciclo da borracha, quando ocorre um amplo fluxo migratório para a região em torno do extrativismo do látex, acentuando a exportação do produto que tanto gerou riqueza e pobreza (Idem, p. 114).
\end{abstract}

A mesma autora (1988) afirma que Belém surge no cenário regional como rota alternativa de força de trabalho não ativa, trazendo um enorme contingente de trabalhadores egressos de várias regiões do Brasil, acentuando a pobreza estrutural da cidade. Nesta correlação de forças antagônicas que perpassam até os presentes dias o desenvolvimento capitalista na Amazônia, ela é viabilizada à integração da economia nacional como fronteira expansionista do capital, sendo uma fonte de matéria prima para exploração, caracterizandose como região parte integrante para o desenvolvimento dos grandes polos industriais. Portanto, a Amazônia e o Pará "integram-se", na perspectiva do capital, à divisão nacional e internacional do trabalho, num processo de inclusão/exclusão (grifo nosso), que rebate no plano social. (Idem, p. 127).

Na década de 1940, no governo de Getúlio Vargas, há uma retomada da economia da borracha, quando declarou um plano de desenvolvimento da Amazônia. Andrade (2010) relembra o discurso nacionalista de Vargas ao afirmar que iria integrar a região amazônica com um programa denominado "Marcha para o O este". De acordo com este mesmo autor, o Presidente visitou o Estado do Pará nesse período para legitimar suas ações.

Segundo Ribeiro, Schneider e Andrade (2013) inúmeras instituições financeiras?? apareceram durante esse período no intento de alavancar o segundo ciclo da borracha, dentre elas o Banco de Crédito da Borracha (BCB), que patrocinou naquele momento parte dos investimentos.

Nesse contexto, se identifica paralelamente ao investimento que gerou desenvolvimento econômico, mas não social, a expulsão de grande parcela da população "não qualificada" do sistema de produção. Esse fenômeno é explicado por Antunes (1995) a partir do desemprego estrutural. Em decorrência disso, as expressões da questão social se intensificam, com o recrudescimento da fome, adoecimento, favelização, enfim, empobrecimento crescente. 
Essa realidade obriga o Estado e o capital a criarem ações tanto de repressão, quanto de gestão da pobreza, fazendo com que haja a necessidade de criação de profissionais para lidar com tais demandas, e o Serviço Social é umas destas profissões que germinam no bojo destas contradições (NETTO, 1992).

Portando, o surgimento do Serviço Social como profissão está vinculado com a Questão Social, pois a necessidade social da profissão está relacionada às desigualdades engendradas e agravadas na ordem burguesa, principalmente no que diz respeito ao binômio industrialização e urbanização. (NETTO, 1992). O Estado do Pará vive um processo de exploração histórica ligada às questões da Amazônia em que o agravamento das desigualdades é analisado tendo como pano de fundo o desmatamento, a exploração das riquezas e a expropriação da terra.

Diante disso, no Estado do Pará a economia é focalizada no setor primário e terciário, sendo o primeiro fortemente ligado ao extrativismo do látex e o segundo ao setor de serviços comerciais (OLIVEIRA, 1988). Esse processo fomenta o desenvolvimento capitalista da cidade de Belém, tornando-a cada vez mais urbanizada por conta dos lucros ligados à exportação da borracha, assim como para abrigar a próspera nova classe burguesa que vivia na capital. Em contrapartida, coexistia uma classe antagônica (trabalhadora) que sofria os impactos da exploração do trabalho e da própria exclusão do mercado de trabalho, como anteriormente mencionado.

No ano de 1946 criou-se no Brasil o Serviço Social do Comércio (Sesc), por meio do decreto de lei no 9853/46, que tinha como pressuposto que "é dever do Estado concorrer, por todos os meios ao seu alcance, para melhorar as condições de vida do coletividade, especialmente das classes menos favorecidas". Entretanto, não se pode perder de vista que as criações dessas entidades de fundo privado para atender os trabalhadores foram uma forma de as classes dominantes continuarem a instituir sua dominação por meio da exploração da força de trabalho da classe-que-vive-do-trabalho' ${ }^{1}$.

\footnotetext{
${ }^{1}$ Este termo é mais bem trabalhado por Antunes em "ADEUS AO TRABALHO? Ensaios sobre as Metamorfoses e a Centralidade do Mundo do Trabalho". 2 Edição. São Paulo: Cortez Editora, 1995.
} 
Naquela época a Unidade Regional do Sesc no Pará tinha como presidente o Professor Dr. Paulo Eleutério Alvares da Silva, fundador da primeira Escola de Serviço Social no Pará em 1951. Segundo Ribeiro (2004), "Paulo Eleutério mantinha contatos profissionais que Ihe fizeram viajar o país em participação de eventos que possibilitaram conhecer escolas de Serviço Social em outros Estados do Brasil", nesse sentido este cargo ao qual ele ocupava, "contribuiu para a criação da Escola de Serviço Social, principalmente por observar que àquela época não se tinha profissionais dessa área na Capital". (Idem, p. 26).

Diante disso, convocou uma reunião da Sociedade de Estudos econômicos do Pará, na qualidade de presidente, no dia 05 de março de 1950, para expor a necessidade de criar uma escola de Serviço Social em Belém. Nesta reunião foram montadas comissões para estruturação do projeto; além disso, o professor Paulo Eleutério chegou a elaborar um relatório justificando a importância de criação de uma escola para "preparação de pessoal técnico indispensável às tarefas do Serviço Social no seio da classe dos auxiliares do cenário". (Memorial da Escola de Serviço Social à Divisão de Ensino superior do MEC, 1954), porém o empreendimento não teve apoio de entidades do Estado, o que o levou a iniciar o empreendimento de forma autônoma, inaugurando a escola no dia 10 de abril de 1950.

Instituições como o Serviço Social do Comércio - Sesc e o Serviço Social da Industria Sesi surgiram no campo da gestão e controle do trabalho de comerciários e industriários, acompanhando processo de modernização já em andamento na Europa e EUA, com o nome de "concertação social” no bojo do Welfare State (NETTO, 1992; BRAVERMAN, 1987)²

A escola de Serviço Social surgiu no ano de 1950, enquanto um projeto formulado pelo senhor Paulo Eleutério. Oliveira (1988) afirma que o mesmo, enquanto intelectual que era, representava uma classe específica, detentora de um projeto de sociedade.

O conceito de intelectual aqui mencionado é o de "intelectual orgânico" em Gramsci (COUTINHO, 2011), este autor acredita que cada classe social produz seus intelectuais "organicamente", ou seja, estes intelectuais atuam para construir a hegemonia de sua classe (PORTELLI, 1990).

Tal afirmação pode ser comprovada na justificativa do próprio idealizador do projeto da escola de Serviço Social, uma vez que ele justificava a criação do curso de Serviço Social em

\footnotetext{
2 O Sesi que criou o primeiro Curso de trabalhadores Sociais na capital do Pará no ano de 1949. (OLIVEIRA, 1988, p. 196).
} 
Belém por entender que seria necessário formar profissionais técnicos para trabalhar no Sesc, instituição da qual ele era gerente, mas não somente isso, mostrava-se preocupado em formar profissionais do "reajustamento humano", como forma de intervir nos "problemas sociais" manifestos naquela década. (MACHADO, 2000).

Verifica-se que ainda que este projeto seja balizado por determinações de ordem pessoal do criador da escola, Oliveira (1988) tinha razão ao afirmar que Paulo Eleutério enquanto intelectual representava a classe a que ideologicamente pertencia, incluindo seu lugar no processo produtivo, que era no favorecimento da reprodução da força de trabalho.

$\mathrm{Na}$ qualidade de líder intelectual e operativo de um projeto de modernização da gestão da força de trabalho, cominando esforços do capital e das nascentes políticas sociais públicas, Paulo Eleutério liderou a criação do primeiro projeto de formação profissional (sem ser assistente social), mas percebeu a necessidade daquela profissão (já estabelecida em muitos países do mundo e no Brasil, desde 1936) para melhorar e modernizar a produção, em particular na indústria e nos serviços. E uma das mediações que se pode explorar, entre tantas outras, é a da linha teórico-metodológica que lastreava esse projeto inicial de formação de assistentes sociais no Pará (Oliveira, 1988).

Segundo Oshai (2000), a influência teórico-metodológica que estava presente na escola de Serviço Social paraense a princípio era funcionalista, mesclada com o ideário católico (doutrina social da Igreja). Ainda que a Igreja Católica não estivesse institucionalmente ligada à criação da escola de Serviço Social à época (como ocorreu na criação da primeira escola brasileira, conforme, lamamoto e Carvalho, 1995), ela também recebe influência da visão social da Igreja, presente na proposta curricular, nos professores e nas primeiras alunas. Isso se percebe na visão da nova profissão como "um sacerdócio", uma vez que as primeiras alunas do curso de Serviço Social eram em grande número lideranças da ação social da igreja em Belém (Oliveira, 1988).

Segundo Oliveira (1988), algumas disciplinas que eram lecionadas, como Ética e Religião, foram ministradas por representantes da Igreja Católica, levando esta influência para a formação profissional das primeiras assistentes sociais paraenses. A mesma autora afirma que nestas disciplinas eram discutidas categorias como Doutrina Social da Igreja e Ética Escolásticas. (Idem, p. 249). 
Entretanto, houve algumas mudanças na escola de Serviço Social no Pará nos anos iniciais de sua existência no que diz respeito a condições políticas, econômicas, estruturais e teóricas. No segundo ano de sua criação, o até então diretor da escola Professor Eleutério entregou sua direção ao Instituto Ophir Loyola ${ }^{3}$ em fevereiro de 1951. No ano de 1953 foi decretada a Lei $N^{\circ} 1.889$ que dispunha "[...] sobre os objetivos do ensino do Serviço Social, sua estruturação e ainda as prerrogativas dos portadores de diplomas de Assistentes Sociais e Agentes Sociais". Nesse sentido, o Instituto Ophir Loyola se viu obrigado a adequar-se às normas estabelecidas.

As escolas de Serviço Social do Brasil, e em consequência a do Pará, precisavam em seu currículo de formação estar compostas das seguintes disciplinas segundo o Artigo $3^{\circ}$ da Lei 1.889/53: I - Sociologia e Economia Social; Direito e Legislação Social; Higiene e Medicina Social; Psicologia e Higiene Mental; Ética Geral e Profissional. II - Introdução e fundamentos do Serviço Social: Métodos do Serviço Social; Serviço Social de Casos - de Grupo - e comunidade: Serviço Social em suas especializações; Família - Menores - Trabalho - Médico e III - Pesquisa Social.

Segundo Oshai (2000), no ano de 1955 o currículo foi alterado e essa modificação se materializou na introdução da metodologia do Serviço Social de caso, grupo e comunidade; portanto, a teoria Funcionalista continua presente na formação do Serviço Social no Pará, seguindo a mesma tendência do Serviço Social brasileiro, agora acatando a influência norteamericana, percebida, segundo a autora, pela perspectiva teórico-metodológica dos trabalhos de conclusão de curso naquele momento.

Dentre essas mudanças que ocorreram na escola de Serviço Social paraense na década de 1950, podemos também destacar o seu reconhecimento pelo Ministério da Educação em 1957 através do decreto $n^{\circ}$ 40.925, uma vez que após esse fato a escola pode formar a primeira turma de Assistentes Sociais. ${ }^{4}$

A escola foi integrada à Universidade Federal do Pará no ano de 1963 através da Lei $n^{\circ} 4283$, já que o Instituto Ophir Loyola não dispunha de condições estruturais e financeiras para manter a instituição de ensino (Oliveira, 1988).

\footnotetext{
${ }^{3} \mathrm{Na}$ década de 50 o Instituto Ophir Loyola funcionava como "Instituto de Proteção e Assistência a Infância do Pará", atualmente o HOL (Hospital Ophir Loyola) é referência no tratamento de câncer adulto e infantil na região metropolitana de Belém, além de ser considerado um Hospital escola no Estado do Pará.

${ }^{4}$ Após o reconhecimento da Escola de Serviço Social concretizou-se a possibilidade de sua filiação à Associação Brasileira de Escolas de Serviço Social (ABESS), atualmente ABEPSS.
} 


\section{Serviço Social no Pará e o Movimento de Reconceituação}

O Serviço Social brasileiro, assim como no Pará, encontra na década de 1960 um contexto marcado por mudanças econômicas, políticas, sociais e culturais que impõem à América Latina um modelo de desenvolvimento excludente e subalterno, ademais de autoritário (NETTO, 2005, 2007).

Diante desta nova realidade, alguns segmentos da profissão reproduzem a ideologia desenvolvimentista, revendo seu método, reconfigurando escolas em vários Estados do Brasil no intento de integrar-se a esta nova perspectiva que naquele momento se tornara hegemônica para a profissão. Nesse período, as reformas de base propostas pelas políticas desenvolvimentistas fomentaram a efervescência dos movimentos sociais.

Todavia, depois da integração do curso à Universidade Federal do Pará, houve impactos no âmbito da formação profissional de assistentes sociais. As instituições de ensino também vinham se integrando à perspectiva hegemônica no plano do desenvolvimento econômico em nível nacional. Tal fato proporcionou ao Serviço Social paraense a possibilidade de aproximação às discussões de outros cursos e perspectivas teóricas das Ciências Sociais (Oliveira, 1988).

O Movimento de Reconceituação do Serviço Social brasileiro, que se integrou ao latino -americano, é o início deste processo de redefinição, pois representou um marco de rupturas com o conservadorismo profissional em todas as dimensões que compõem a profissão, sendo este considerado um processo de revisão crítica do Serviço Social no continente Latino Americano (IAMAMOTO, 1998, p. 205).

A autocrítica do Serviço Social brasileiro e latino-americano gesta-se em um contexto marcado por significativas mudanças nos campos social e político, presidiada pela efervescência dos movimentos sociais e demarcada pela expansão do capital nacional. No Pará esse processo se dá também marcado pela expansão do grande capital. Este momento mostra-se, segundo Ribeiro, Schneider e Andrade (2013), distante da realidade Amazônica, o que rebateu no plano social, causando grandes lastros de desigualdade. 
Tal processo traduz-se pela política dos governos militares-civis da ditadura do grande capital conhecido como os "Grandes Projetos na Amazônia", que assinalaram a instalação do modelo de "enclaves" na economia da região, impulsionador de grandes lucros para megainvestidores da área da mineração nacional e internacional, deixando um rastro de destruição do meio ambiente, e um pífio resultado de socialização das imensas riquezas extraídas do solo e do trabalho da Amazônia. (Castro, 2012)

Portando, o Movimento de Reconceituação de corte marxista caracteriza-se também como um movimento de denúncia e questionamento de uma realidade macro societária, que tinha como projeção a construção de um novo Serviço Social diante dessas transformações. (IAMAMOTO, 1998).

Ressalta-se que esse trabalho se baseou na interpretação do Prof. José Paulo Netto em Ditadura e Serviço Social (2007), o qual interpreta o referido movimento de reconceituação por meio de três vertentes teóricas, quais sejam: modernização conservadora, reatualização do conservadorismo e intenção de ruptura. Considerando a primeira vertente intitulada modernização conservadora, a saber: de cunho positivista e estrutural funcionalista, cabe ressaltar que seus representantes se autointitulavam como profissionais modernos, cuja legitimação advém menos de uma "auto" representação humanista abstrata do que de uma fundamentação teórico-técnica do exercício profissional. Esta perspectiva teóricometodológica está contida nos documentos de Araxá $^{5}$ e Teresópolis ${ }^{6}$.

No documento de Araxá o que marca é a perspectiva de globalidade, evidenciando o aspecto teórico do Estrutural-funcionalismo, uma vez que esta corrente teórica trabalha com a ideia de indivíduos desajustados, na qual o todo é a soma das partes, ou seja, a sociedade é como o todo, e quando umas das partes do todo não se enquadra o Serviço Social deve trabalhar no sentido de integração, o que requer conhecimento acerca da realidade social para que seja efetivada essa intervenção.

\footnotetext{
${ }^{5}$ O 1 ㅇ Seminário de teorização do Serviço Social promovido pelo Centro Brasileiro de Cooperação e Intercâmbio em Serviço Social (CBCISS), que ocorreu no Brasil, de 19 a 26 de março de 1967, em Araxá/MG, possibilitou várias discussões epistemológicas que estão contidas no chamado documento de Araxá [...] neste documento a prática profissional se caracteriza por ação junto a indivíduos e famílias desajustadas. (PEREIRA e SARDINHA, p. 26. 2013).

${ }^{6}$ O 2o Seminário de Teorização do Serviço Social, também realizado pelo Centro Brasileiro de Cooperação e Intercâmbio em Serviço Social, na década de 1970, na cidade de Teresópolis/RJ, possibilitou discussões epistemológicas, apresentando a metodologia do Serviço Social como "método científico aplicado", ou seja, opera através do diagnóstico e intervenção planejada. (PEREIRA e SARDINHA, p. 27. 2013).
} 
No entanto, o Documento de Teresópolis recebe grande influência também da teoria Sistêmica (expressão atualizada do neopositivismo); destaca-se neste segundo a razão instrumental como primordial, na qual a racionalidade profissional deve estar alçada em uma perspectiva racional cibernética.

A segunda vertente do movimento de reconceituação, indicada por Netto (2007) denomina-se reatualização do conservadorismo, que se mostrou expressiva no seminário de Sumaré ocorrido no ano de 1978 e no Seminário do Alto da Boa Vista ocorrido na década de 1980, ambos realizados no Rio de Janeiro. Para Santos (2006) a centralidade das discussões teóricas desses eventos se expressa na preocupação em elaboração teórica sobre a prática profissional, sendo esta produção do conhecimento baseada na influência da fenomenologia ${ }^{7}$.

De acordo com Santos (2006) o método dialógico considera que no espaço do diálogo duas pessoas são percebidas como sujeitos, os quais provocam a situação existencial problematizada (SEP). Portando, nesse encontro de diálogo a pessoa/profissional intercambia conhecimentos, ações e sentimentos, possibilitando a caracterização deste momento e uma ação profissional distante do modelo norte-americano de caso-grupo e comunidade, já que é uma relação entre sujeitos mediatizado pela intencionalidade entre consciências em construção.

No entanto, a terceira perspectiva do movimento denominada por Netto (2007) como intenção de ruptura vinha no sentido de romper com a tradição intelectual conservadora do Serviço Social de base funcionalista-católica. Baseado na influência marxista, iniciada em meados da década de 1960. A aproximação do Serviço Social ao debate marxista se realizou pela proximidade de assistentes sociais de vanguarda a movimentos sociais e à militância em partidos comunistas na resistência à ditadura militar (NETTO, 2007).

Nessa esteira, essa aproximação ao marxismo se deu da forma possível à época, utilizando-se principalmente das fontes secundárias disponíveis, que se por um lado ampliavam a visão crítica à sociedade burguesa e propunham sua superação, por outro não dotavam da melhor visão teórico-metodológica enquanto teoria social, porque tal perspectiva, conhecida como marxismo vulgar, distorcia algumas categorias essenciais,

\footnotetext{
7 Anna Augusta de Almeida foi a principal expressão dessa corrente na profissão em Método Dialógico: possibilidades e limites da teoria do Serviço Social”, Rio de Janeiro, Ed. Francisco Alves, 1978.
} 
especialmente no método dialético (PONTES, 2017) para melhor interpretação e ação no campo político e profissional (NETTO, 2007).

No Brasil, essa última influência se revela teórica e praticamente na formulação da proposta do "Método de Belo Horizonte" em 1972 na Universidade Católica de Minas Gerais (PUC/MG). Emerge como um contraponto às perspectivas consideradas por essa vertente do Movimento de Reconceituação como "conservadoras". No entanto, devido ao processo tumultuado pós-golpe militar de 1964, eram escassas as possibilidades de acesso a obras marxistas, fazendo com que por vezes o acesso ao marxismo fosse feito através de análises equivocadas de suas obras.

O desconhecimento efetivo das concepções marxistas possibilitou alguns equívocos profissionais àquela época, como o ativismo político, que reverbera em conceber o fim último das dimensões políticas do exercício profissional como ofício heroico e/ou messiânico. (NETTO, 2007). Mas, ainda que houvesse equívocos epistemológicos nas visões analíticas da categoria, a terceira vertente da chamada Reconceituação da profissão deve ser entendida em uma perspectiva de totalidade, e sem fatalismo, uma vez que esta era a que tensionava as mudanças na visão de mundo do conjunto da categoria sobre a realidade.

No Pará, o movimento reconceituador foi marcado por inúmeras particularidades. Assim, com vistas a evidenciar tais aspectos, o trabalho que consubstanciou a elaboração deste artigo contou com a colaboração de três docentes que vivenciaram esse momento histórico e que compartilharam essas experiências por meio de entrevistas. Essas vivências foram relatadas abordando os seguintes aspectos: os momentos de rupturas com o conservadorismo e suas contradições, a forte influência da abordagem fenomenológica no processo de tensionamento com a perspectiva marxista, o significado da reconceituação e o acesso a uma perspectiva teórica crítica e que deu subsídios para o fortalecimento e construção do Projeto ético-político profissional.

Santos (2006) afirma que no momento de ruptura que se tencionava os elementos ideopolíticos do marxismo, principalmente os que vieram a partir da militância política, "caíram como uma luva" para justificar ideologicamente a necessidade de superação da neutralidade profissional. Sobre isso, a Profa. Entrevistada 1 destacou que os processos de ruptura com o conservadorismo aqui no Pará, se deram principalmente por vias do movimento estudantil, dada a efervescência dos movimentos sociais da década de 1960. 
Diante disso, a professora acima referida afirma que "outro referencial aqui no Pará despontou para contestar o método dialético e as referências conceituais de origem marxiana com a chamada 'fenomenologia'. Neste sentido, é importante assinalar que o Movimento de Reconceituação do Serviço Social brasileiro construiu-se sob a égide de antagonismos teóricos, assim como embates ético-políticos, porém a ruptura com o conservadorismo que se tornara hegemônico no bojo da profissão nas décadas de 1980/90 só foi possível segundo lamamoto (1998) pelo aprofundamento teórico das premissas do propósito do Movimento de Reconceituação.

Sabe-se que o movimento de renovação do Serviço Social foi um movimento global de crítica e remodelação das bases constitutivas da profissão (IAMAMOTO, 1998). Mas que reverberam até os dias atuais em reatualizações socioprofissionais em nível de formação e exercício profissional. Assim, avalia-se que o debate sobre esse processo não está encerrado, sobretudo na cena contemporânea quando despontam reatualizações conservadoras, a exemplo das teorias pós-modernas, no âmbito das ciências sociais.

Por meio de sua renovação o Serviço Social buscava não sucumbir à realidade que se colocava naquele momento. Nas palavras de lamamoto (1998) "o Serviço Social buscava assegurar sua própria contemporaneidade" (p. 202). É nesse sentido que a professora 03, quando perguntada sobre a gênese do movimento de reconceituação no Pará nos relata que:

[...] eu acho que tem a ver com a Ditadura que eu acho que é um caminho mais radical, de certa forma, foi uma estratégia da própria categoria, estudando o que é teoria, o que é método, então nós fomos estudando o que era epistemologia, e fomos por dentro do conhecimento pra dizer: será que o Serviço Social é teoria? Serviço Social tem método próprio? O que é isso? Então essas questões de certa forma faziam a gente ter um foco.

Assim, segundo ela, o movimento de renovação do Serviço Social caracterizou-se como uma estratégia da categoria profissional de enfrentamento da ditadura militar instaurada na América Latina, nas suas palavras era uma estratégia "para que nós pudéssemos com isso construir conhecimentos que fossem mais próximos da realidade brasileira, no sentido de enfrentá-la" (Profa. 03).

Essa estratégia se deu por meio dos estudos teóricos a princípio elencados em perspectivas positivistas/funcionalistas conforme relatos da professora 03 "a perspectiva que 
influenciou o movimento de reconceituação era funcionalista". Outro importante destaque atribuído pela professora para a consolidação do movimento foram as entidades organizativas da categoria, com destaque para a ABESS que organizava encontros e debates:

[...] pra discutir sobre a teorização do Serviço Social, pelos documentos de Araxá, documento de Teresópolis, esses documentos foram feitos ainda na época em que não se falava em método marxista, se falava na busca da teoria. Essa insatisfação no movimento, com base ainda no funcionalismo para romper com o modelo NorteAmericano, essa era a questão (Profa. 03).

Citou a convenção da ABESS do ano de 1958, que ocorreu em Piracicaba, como um marco nessa direção social, pois naquele momento a associação já sugeria que as escolas de Serviço Social tivessem uma direção mais crítica, seguindo novos rumos teóricometodológicos:

Em 58 a convenção de ABESS em Piracicaba sugere que as escolas de Serviço Social deem atenção especial ao sólido conhecimento da conjuntura socioeconômica brasileira, maior desenvolvimento ao processo de Serviço Social de Comunidade, conhecimento mais extenso em administração de Serviço Social, conhecimento da implicação de outras profissões no Serviço Social, treinamento em equipe, técnica de penetração nas massas especialmente as de educação de base (Profa. 03).

Isso se explica pelo fato de o movimento de reconceituação ter sido altamente polarizado, no que diz respeito às posições teóricas, e, nesse momento já despontava no bojo da categoria "um contexto que vem trazendo pro Brasil a insatisfação da América Latina" (Profa. 03). E ela continua dizendo que:

[..] a gente achava que estávamos acomodando os trabalhadores com esse tipo de trabalho que a gente desenvolvia, a gente acomodava a população e não fazia com que ela se libertasse enquanto sujeito.

Assim, surge no movimento de reconceituação do Serviço Social a vertente que a professora em questão chama de "inquieta, e que passa a estudar as estruturas da sociedade, o que tá por trás de tudo aquilo". Esse giro epistemológico no bojo da categoria se explica, sobretudo, pela inserção de boa parte da classe nos movimentos de esquerda socialista. Conforme lamamoto (1998) "o encontro do Serviço Social com a perspectiva crítico-dialética deu-se por meio do filtro da prática político-partidária" (p. 210). 
Sobre isso a professora 01 nos relatou que o movimento de reconceituação no estado do Pará teve importante participação da categoria estudantil, sobretudo pela sua inserção nos movimentos sociais e entidades organizativas como a UAP e a UNE. Ela nos diz que:

No Pará o movimento entrou com a adesão imediata dos estudantes do Curso de Serviço Social, mais do que dos professores. Um Serviço Social reconceituado condizia mais com o clima de intensa politização e mobilização dos estudantes e sindicatos do Pará".

Assim, de acordo com lamamoto "tal questionamento se gesta no contexto das profundas mudanças que se operavam no nível continental, presidida pela efervescência das lutas sociais" (p. 206, 1998). De acordo com a professora 01:

Existem duas raízes da gestação dessa crítica, ambas vinculadas ao movimento latino-americano de extrema sedução do ideário socialista, que em 1959 resultou na revolução cubana e que teve na militância de Guevara muitas ações para que isso acontecesse em outros países da América Latina: A primeira raiz advém dos estudos e das elaborações, no campo do Serviço Social e da Sociologia, de conteúdo crítico, publicadas pela ALAIETS e CELATS; A segunda está relacionada à militância dos estudantes de Serviço Social na UAP (União Acadêmica Paraense), vinculada à UNE (União Nacional dos Estudantes). Como participantes do Diretório Acadêmico de Serviço Social, engajamo-nos nessa militância de corpo e alma. Frequentávamos a UAP todos os dias até de madrugada discutindo política estudantil e luta pelo socialismo. Por isso eu costumo dizer que o movimento de reconceituação do Serviço Social no Pará começou pelos estudantes e não pelos professores. Passamos a questionar a teoria do Serviço Social de então. Lembro-me que fui expulsa de uma aula de Serviço Social de Grupo porque questionei o positivismo da teoria adotada pela docente.

Nesse sentido, pode-se dizer que o ideário socialista latino-americano da década de 1960 fez os estudantes despontarem nessa empreitada, em conjunto com uma vanguarda da categoria que já estava envolto da perspectiva crítica de influência marxiana.

Todavia, as visões da reconceituação não foram comuns: na contramão das análises supracitadas, a professora 02 afirma que a reatualização profissional tem suas raízes vinculadas à Igreja Católica conforme relato a seguir:

Esse movimento surge a partir de 1960 e, ele pega a América Latina todinha, influenciado por quem? Pela Igreja Católica Carismática, é o questionamento desse homem [...] não só a Igreja, mas também a Política com o PT (Profa. 02). 
A referência feita pela professora 02 , sobre a gênese do movimento de reconceituação ligado à Igreja Católica, não foi encontrada pelos pesquisadores deste trabalho em nenhuma literatura do Serviço Social.

Embora tenha sido um movimento de questionamento ao tradicionalismo profissional, a reconceituação não foi homogênea, sobretudo por se tratar de uma organização que se perfila em uma conjuntura adversa, no período da ditadura militar, recebendo influência direta desse período que tinha um projeto de ideário modernizador/conservador.

Assim, outros referenciais teóricos despontaram, além das teorias positivistas e da teoria social crítica marxiana, notadamente, no Pará "a fenomenologia despontou para contestar o método dialético e as referências conceituais de origem marxiana. Sobre isso a professora 02 nos relata que:

Eles começaram a dividir, era o positivismo/funcionalismo/pragmatismo, marxismo [...] e a fenomenologia com os existencialistas, então ficaram querendo brigar lá dentro, porque o pessoal que ficou muito na docência e não teve experiência de campo, a maioria daquele pessoal que tá no discurso não teve experiência de campo, então como não teve experiência de campo se agarra em um livro e fica só naquele livro e naquela teoria.

Nesse mesmo sentido a professora 03 afirma que "dentro da faculdade chegavam a ter momentos de tensão e enfrentamento". A professora 01 nos relatou que "quanto mais se acirravam os enfrentamentos, mais o grupo marxista se aprofundava nos estudos da teoria social crítica".

É nítido, na fala das professoras, que o envolvimento delas no movimento estudantil favoreceu a apreensão da teoria social crítica, mesmo que de forma embrionária, como relatado pela professora 03 , mas que potencializou com que despontasse no bojo da reconceituação a vertente de pensamento marxiano. Conforme ela nos relata:

Os estudantes também têm muita influência no processo de reconceituação no Pará, pois eles caminhavam de uma forma diferenciada das próprias instituições, [...] a participação dos estudantes na diretoria de ABESS e, questionando. O próprio envolvimento dos estudantes no movimento social que levava influências teóricas para os encontros de ABESS.

No que tange à participação e influência do movimento estudantil nesse debate, observa-se que as professoras analisam esse processo de forma semelhante. A profa. 01 nos relata como se dava essa construção quando ainda era estudante de Serviço Social: 
Abracei o movimento de reconceituação desde quando ainda era estudante de Serviço Social. Fui presidente do Diretório Acadêmico de Serviço Social e o nosso grupo de Diretoria, formado, além de mim, por Almerinda Palha Freire (mais tarde presa pela ditadura - hoje falecida), Maria de Lourdes Couceiro Simões (também presa) e por Yolanda Shirley Cunha, ingressou numa apaixonada radicalidade. Começamos desde então a nos aprofundar nos estudos da teoria crítica e do método dialético.

Apesar de vários avanços com a interlocução da profissão com o marxismo e a teoria marxiana, observa-se que a apreensão da professora 02 sobre essa aproximação não foi satisfatória. Para ela, a aproximação com a teoria social crítica foi prejudicial ao movimento de reconceituação:

Eu acho que a Reconceituação, naquele momento foi importante, porque abriu o horizonte para ter outra visão de mundo, mas no momento que ele ficou demais no marxismo e na dialética, só dizendo a mesma coisa, não é dialética mais, já mudou.

Segundo a mesma professora, "o Serviço Social deve ter uma visão ampliada, e não se fechar em uma só teoria, em um só tipo de conhecimento". Para ela o legado da reconceituação foi importante, mas "não deveria ter parado no tempo". Aproveitou para afirmar que dentre as posições teóricas ela "não assume nenhuma", pois acredita que uma só teoria não consegue dar conta da realidade.

Nunca fiz parte de nenhuma corrente, trouxe todos os professores de dialética, de fenomenologia, e, levei para UNAMA, não defendia nenhuma das correntes, não era neutralidade, mas da maneira como eles assumiam [...]. Não tem por que eu estar brigando (Profa. 02).

Assim, verifica-se, de acordo com a fala dos sujeitos entrevistados, que o conjunto das diferentes influências teóricas levaram o Serviço Social, aqui mais especificamente os sujeitos entrevistados, a interpretarem o movimento de reconceituação de diferentes formas. Nota-se, que até mesmo as protoformas sobre as quais se vinculam esse movimento são vistas de forma diferente pelas professoras.

Cabe mencionar que as três entrevistadas foram unânimes ao falar sobre os referenciais teóricos que disputavam a hegemonia no movimento de reconceituação: positivismo, funcionalismo, fenomenologia e marxismo, movimento que acompanhou o 
debate da profissão em todo o país. Todavia, observa-se que duas entrevistadas apresentaram linhas de análise semelhantes com relação à importância da interlocução do marxismo/ marxiana com a profissão, assim como a importância do movimento estudantil nessa construção.

\section{Considerações Finais}

Considerando os resultados da pesquisa verificou-se que o movimento de reconceituação no estado do Pará foi altamente polarizado, com diferentes visões ideológicas e teórico-políticas. Notadamente, as principais correntes teóricas que impulsionaram esse movimento foram as teorias de ordem positivistas, fenomenológicas e marxistas.

É notório nas produções do Serviço Social contemporâneo que, no pósreconceituação do Serviço Social brasileiro, a teoria social crítica de origem marxiana despontou sua hegemonia no processo de formação profissional. Comprova-se isso por meio do Projeto ético-político que se consolidou em meados da década de 1990 na profissão.

No Pará, a influência marxiana também foi evidenciada na pesquisa, por meio dos aspectos histórico-metodológicos apresentados pelos sujeitos entrevistados, os quais evidenciaram fortes rebatimentos da tendência marxiana no processo de intenção de ruptura com o conservadorismo teórico, colocado naquele período enquanto possibilidade de modernização das práticas profissionais, especialmente a partir das teorias de cunho positivista e estrutural funcionalista.

A pesquisa que ora se apresenta demonstrou que, durante todo o percurso histórico da profissão no estado do Pará, diferentes correntes teóricas influenciaram a formação e disputaram hegemonia. O estudo da visão de professores aposentados da UFPA comprovou uma gama de vertentes, que corroboram em antagônicas interpretações sobre o Serviço Social e seu processo histórico.

Contudo, evidencia-se que a tendência marxista se apresenta, desde suas primeiras aproximações com a profissão, como aquela que favorece uma interpretação mais fiel e radical sobre as determinações da realidade que impactam a profissão e o trabalho profissional do assistente social. Isso pois, foi a partir da fala dos sujeitos entrevistados, ligados à tradição marxista, que se visualizou uma interpretação crítica e histórico-metodológica 
sobre a profissão como parte e expressão das determinações reais do movimento da realidade social do Brasil e em particular da Amazônia.

\section{Referências}

ABESS. ENSINO EM SERVIÇO SOCIAL: pluralismo e formação profissional. Ed. Cortez, São Paulo, 1991.

ANTUNES, R. ADEUS AO TRABALHO? Ensaios sobre as Metamorfoses e a Centralidade do Mundo do Trabalho. $2^{\circ}$ Edição. São Paulo: Cortez Editora, 1995.

ARBEX JÚNIOR, J. "Terra sem povo", crime sem castigo. In: TORRES, Mauricio (Org). Amazônia revelada: os descaminhos ao longo da BR-163. Brasília: CNPq, 2005.

BRASIL, Decreto de Lei № 1889 de Junho de 1953. Orientação Metodológica para a formação profissional dos Assistentes Sociais. Diário Oficial [da república federativa do Brasil]. Brasília/DF, 1953.

BRASIL, Decreto de Lei N 4283 de novembro de 1963. Referente à integração da Escola de Serviço Social do Hospital Ophyr Loiola à Universidade Federal do Pará. Diário Oficial [da república federativa do Brasil]. Brasília/DF, 1963.

BRASIL, Decreto de Lei № 4283/63. Brasília/DF, 1963.

BRASIL, Decreto de Lei № 9853/46. Referente à criação do Serviço Social do Comércio (Sesc). [República federativa do Brasil]. Brasília/DF, 1946.

BRASIL, MINISTÉRIO DA EDUCAÇÃO. Diretrizes Curriculares para os cursos de Serviço Social. Brasília/DF, 2002.

BRASIL. Decreto - Lei n 40.925 de 1957. Brasília/DF, 1957.

BRAVERMAN, H. Trabalho e capital monopolista - a degradação do trabalho no século XX. Rio de Janeiro. Ed. Guanabara, 1987.

CASTRO, E. Expansão da fronteira, megaprojetos de infraestrutura e integração sul-americana. Caderno CRH, v. 25, n. 64, p. 45-62, 2012.

GRAMSCI, A. O leitor de Gramsci: escritos escolhidos 1916-1935. Organização e Introdução de Carlos Nelson Coutinho. Rio de Janeiro: Civilização Brasileira, 2011.

FONTANELLA, B. et al. Amostragem em pesquisas qualitativas: proposta de procedimentos para constatar saturação teórica. Cad. Saúde Pública, Rio de Janeiro, 27(2):389-394, fev., 2011. 
IAMAMOTO, M.; CARVALHO, R. Relações Sociais e Serviço Social no Brasil: esboço de uma interpretação histórico-metodológica. 10 Edição. São Paulo: Cortez, 1995.

IAMAMOTO, M. A formação acadêmico-profissional no Serviço Social brasileiro. Serviço Social e Sociedade, São Paulo, n. 120, p. 609-639, out./dez., 2014.

O Serviço Social na contemporaneidade: trabalho e formação profissional.

São Paulo. Cortez. 1998.

IBGE, 1960. Contagem Populacional de 1960. Instituto Brasileiro de Geografia e Estatística, dados referentes ao município de Belém/PA, fornecidos em meio eletrônico. Disponível em: http://www.ibge.gov.br/home/. Acesso em: 10 fev. 2016.

MACHADO, M. PAULO ELEUTÉRIO ÁlVAREZ DA SILVA: Fundador da Escola de Serviço Social do Pará. Programa de Pós Graduação em Serviço Social da Universidade Federal do Pará, Belém/PA, [2000]. Trabalho manuscrito.

MEMORIAL DA ESCOLA DE SERVIÇO SOCIAL À DIVISÃO DE ENSINO SUPERIOR/MEC, 1954.

NETTO, J. P. Capitalismo Monopolista e Serviço Social. São Paulo. Cortez, 1992.

NETTO, J. P. Ditadura e Serviço Social: uma análise do Serviço Social no Brasil pós $64.11^{\circ}$ Edição. São Paulo: Cortez, 2007.

. O Movimento de Reconceituação 40 anos depois. Revista Serviço Social e Sociedade. São Paulo. P. 05-20, nov. 2005.

OLIVEIRA, E. PERSPECTIVAS HEGEMÔNICAS E INSTITUCIONALIZAÇÃO DO SERVIÇO SOCIAL NO PARÁ. Dissertação (Curso Internacional de Mestrado em Planejamento e Desenvolvimento) Núcleo de Altos Estudos Amazônicos - NAEA, Universidade Federal do Pará - UFPA, Belém/PA, 1988.

OSHAI, C. A institucionalização do Serviço Social como Profissão no Estado do Pará: Contexto, trajetória e influência. Programa de Pós Graduação em Serviço Social da Universidade Federal do Pará, Belém/PA, [2000]. Trabalho manuscrito

PEREIRA, G.; SARDINHA, N. DIRETRIZES CURRICULARES E PROJETO PEDAGÓGICO DO SERVIÇO SOCIAL: um estudo preliminar de suas contribuições na dimensão teórico-metodológica dos assistentes sociais formados em 2009. Trabalho de conclusão de Curso apresentado a Faculdade de Serviço Social da UFPA, 2013.

PONTES, R. N. Mediação e Serviço Social. 8a. Ed. São Paulo: Cortez, 2017.

PORTELLI, H. Gramsci e o bloco histórico. 5. ed. Rio de Janeiro: Paz e Terra, 1990.

RIBEIRO, A. SCHNEIDER, L. E ANDRADE, C. Amazônia: Políticas de Desenvolvimento e Destruição. História e-História, P. 36-54 v. -, p. http://www.hist, 2013. 
RIBEIRO, E. HISTÓRIA DO SERVIÇO SOCIAL NO HOSPITAL OPHIR LOIOLA. Dissertação (Mestrado em Serviço Social). Programa de Pós-Graduação em Serviço Social - PPGSS, Universidade Federal do Pará - UFPA, Belém/PA, 2004.

SANTOS, C. M. Os instrumentos e técnicas: mitos e dilemas na formação profissional do assistente social no Brasil. 2006. Tese de Doutorado da Escola de Serviço Social do Rio de Janeiro, 2006.

UFPA. Projeto Pedagógico do Curso de Serviço Social. Instituto de Ciências Sociais Aplicadas/Faculdade de Serviço Social. Belém/PA, 2005.

Recebido em: 21.06.2020

Aceito em: 18.12.2020 